\title{
TEACHING PRONUNCIATION WITH AN OSCILLOSCOPE
}

\author{
by Kathleen Alberston
}

Sound discrimination, the foundation of pronunciation training, often becomes a frustrating stumbling block for students unable to distinguish the difference between two phonemes or allophones of the same phoneme. In addition, the challenge of assisting the student in discrimination skills often instills a sense of helplessness in instructors whose students can not seem to hear their own mistakes.

In an attempt to relieve some of the pressure caused by these problems, I am using the Kay Elementrics Visi-Pitch to teach the pronunciation of American English. With it, the students are able to see some of the distinctions they were unable to hear. They can compare the display of their pronunciation attempts to the model produced by the instrucor.

\section{What is a Visi-Pitch}

The Visi-Pitch is a pitch and amplitude extraction device which is used with a modified Tectronix storage oscilloscope. The speech signals are received through a hand held microphone and the pitch and amplitude can be displayed separately or simultaneously on the vertical axis of a $4 "$ " $5^{\prime \prime}$ screen, over time, which is displayed on the horizontal axis. When both are displayed together, pitch can be seen as a solid line while the amplitude as a dotted line. The pitch band can be adjusted from low to high frequency levels to accommodate the variation of fundamental frequencies of persons using the instrument.

Because the scope has a split screen with storage and automatic erase capabilities, the trace of the instructor can be stored on one section of the screen while the student tries repeatedly to match it on the other, with each attempt erasing the former trace. Because the utterance is displayed within a small fraction of a second from the instant it was spoken, the feedback is virtually immediate and the students can learn to maneuver the trace with their voice and air-flow, and thereby improve their pronunciation. The length of the trace time can be varied from one to eight seconds so that a single word can be displayed on the width of the screen, or an utterance of several sentences can be recorded. 


\section{Prosodic Features}

Because the nonphonemic errors cause the second language learner to be "not understood" more than the phonemic variations cause him to be "misunderstood" (Prator and Robinett 1972:xii), it is in this area that we seem to spend the most time and have found the Visi-Pitch to be the most useful. This is particularly true in the rhythmic patterns of polysyllabic words. Although pitch could be a factor, we use the amplitude setting alone in this application and concentrate on the length and volume features of stress. We have seen emphasis on a syllable as an increase in length, or volume, or have found both working together. Hence in the word "development," stress can be seen as a lengthening of the second syllable as well as an increase in volume on that syllable. However, in the word "danger," the stressed first syllable can be seen as significantly lengthened, but the second syllable has equal if not greater amplitude even though it is reduced in length. These featyres are difficult to hear, especially if they are nondistinctive in your native language.

\section{"development"}

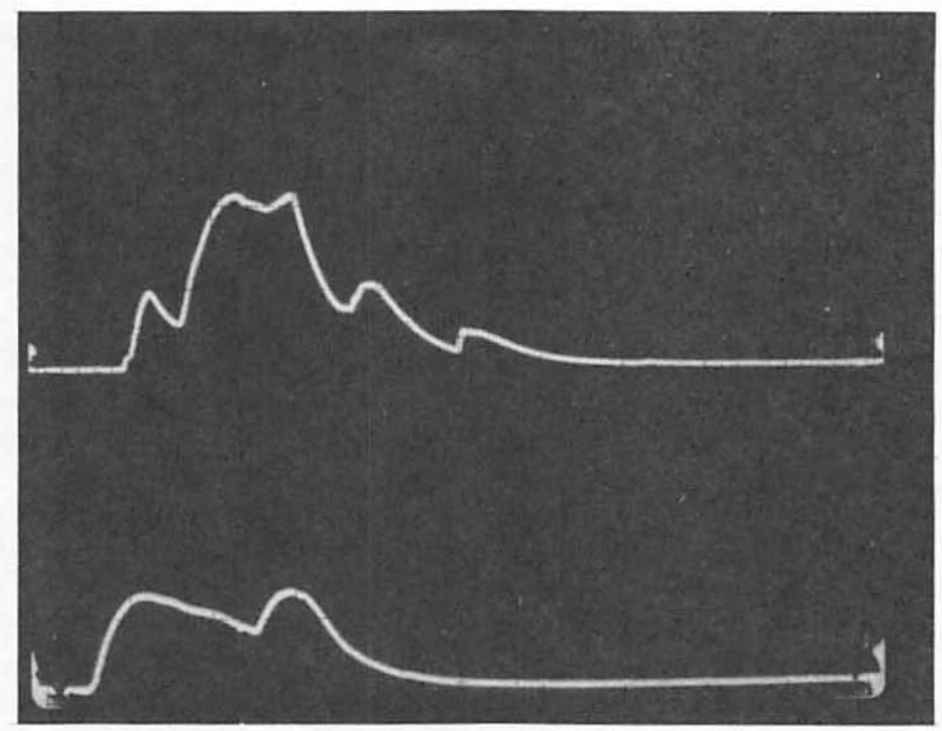

"danger" 
As we progress from words in isolation, to the combination of appropriate words into thought groups, we continue to use the Visi-Pitch on the amplitude setting. Students are able to see whether or not they have been successful at blending as a failure to do so allows the trace to drop to the voiceless position on the bottom of the screen.

The stress and reduction characteristics of content and function words in sentence stress can also be seen with the display of amplitude. When pitch is added to the display, its contribution to sentence stress can also be seen.

Because intonation patterns vary from one language to another, carrying with them emotional overtones, it is important to give them some consideration. We do so by using the amplitude as well as the pitch setting so that we can see where we were in the sentence when the pitch changed. Would you like to be a computer programmer. As mentioned before, the pitch is displayed as a solid line while the amplitude is seen as a dotted line.

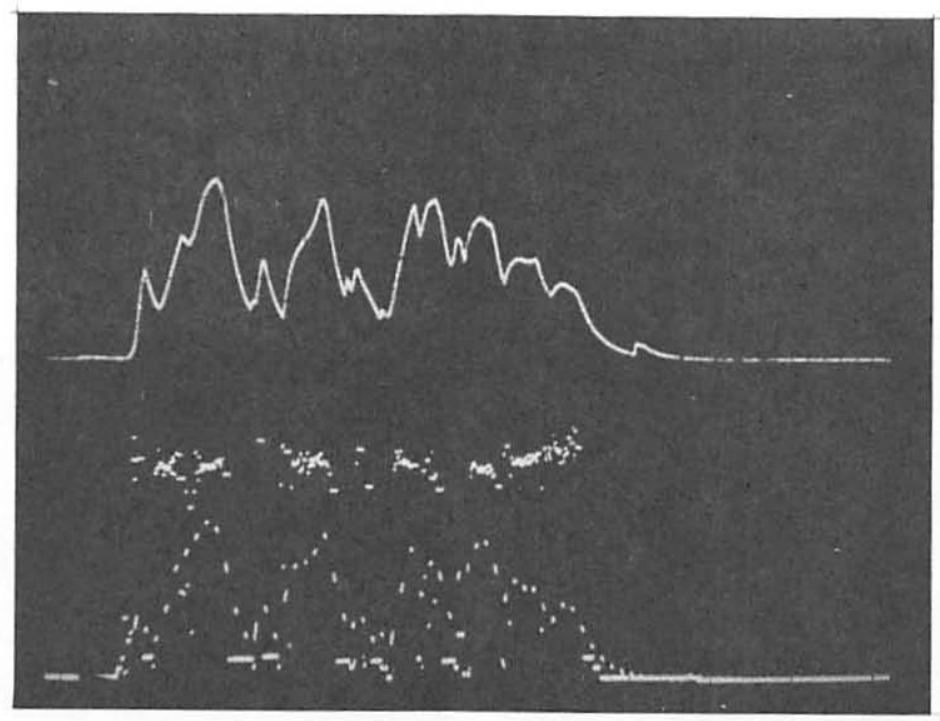

"Would you like to be a computer programmer?" upper: amplitude only lower: amplitude and pitch 


\section{Phonemic Features of Consonants}

Although the Visi-Pitch does not show traces unique to individual phonemes; when used on the amplitude setting, it does show the differences between the target phonemes and some of the most frequent substitutions for them. For example, there is a consistent variation between voiced consonants and their voiceless counterparts. Hence, there are different traces for "putter" and "butter", "Kate" and "gate", "Dick" and "tick".

Where there is a difference in the amount of air-flow a difference can also be seen on the amplitude setting. There is an obvious difference in the displays of "tink" and "think".

\section{Allophonic Features of Length and Aspiration}

Because the allophonic features of American English we have found to be most troublesome have dealt with aspiration and length, features visible with the amplitude display, the instrument has been helpful here also. An unaspirated / $/$ / before a stressed vowel that is often heard as a $/ d /$, is seen as looking similar to the $/ d /$ trace. The difference in vowel length before the voiced and voiceless stops is also quite clear on the screen although it is somewhat difficult to hear.

In general, because the trace is activated by voicing or by the flow of the breath stream into the microphone, anytime that these two factors vary, there will be a change in the trace on the amplitude setting.
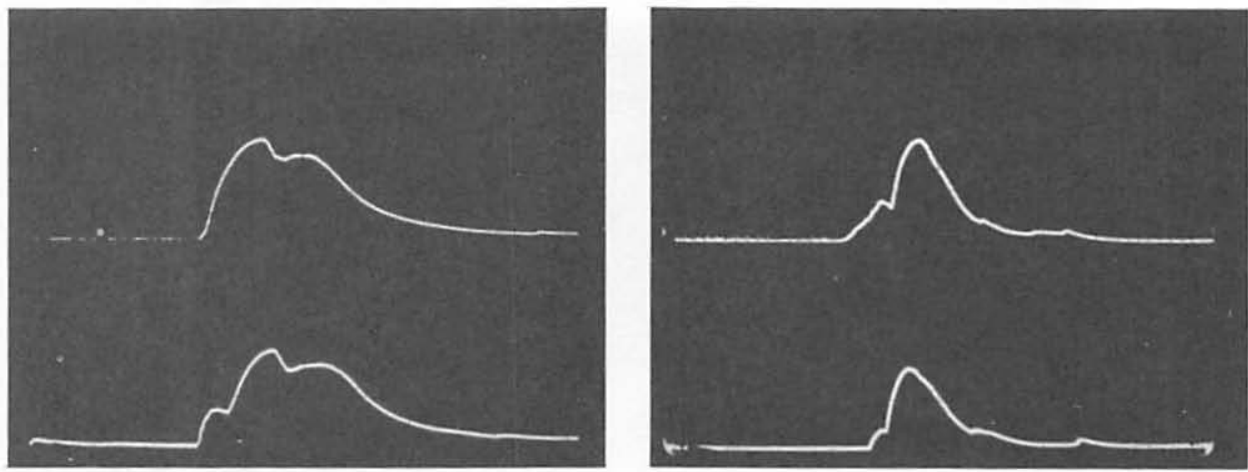


\section{What About the Vowels?}

As stated previously, the Kay Visi-Pitch is a pitch extraction device with a four band adjustment feature ranging from $A$ for the lower frequency voices of most adults, through $D$ for the higher frequency voices of infants. When the instrument is adjusted to the appropriate settings, a digital readout appears giving the precise fundamental frequency of the voice of the speaker, information valuable to speech pathologists for whom the instrument was basically designed.

However, when the instrument is used out of range, that is, with a mature lower frequency voice on the highest frequency band intended for the higher voices of children, multiple traces appear that will vary with the production of the various vowels. When the intensity setting of the scope is also put out of adjustment by setting it higher than normal, a solid band appears rather than the multiple traces, giving single heavy traces that can be easily seen to vary significantly from one vowel to the other. This is true not only of the simple vowels but of the diphthongs as well, where a definite glide from one vowel to the other can be seen.

Although the traces may vary slightly from one voice to another, the relative variation between vowel sounds seems to be consistent. Each student can see a difference between /i/ and / //, and with the production of /ai/, can see his movement from /a/ to /i/.

"heed, hid, head, had, hod, hawed, hood, who'd; pitch out of range

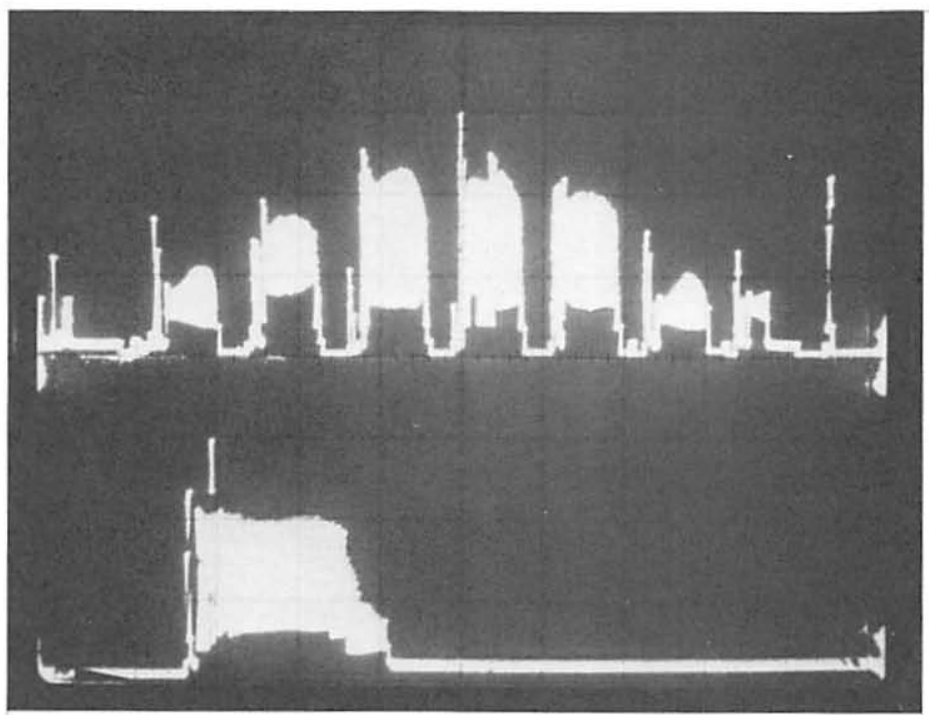

"ai" pitch out of range 
There are questions at this time as to why this phenomenon should occur, as it is not within the design of the machine to indicate vowel differences. Also, it is not clear what relationship exists between the formant frequencies and the vowel traces. However, the occurence seems to be consistent and repeatable for each adult voice tried so far. Even though the technological facts remain to be sorted, it does not diminish the fact that the vowel displays are exceedingly helpful in pronunciaion training. It must laso be mentioned, that until more data has been gathered regarding the use of the Visi-Pitch in this manner, the manufacturer will make no claims regarding its reliability in this application.

\section{Language Lab Applications}

Although I have not done so, it is possible to use the Visi-Pitch in a Language Lab arrangement. It is designed with a receptacle for a tape recorder so that a recorded signal can be fed into the instrument without outside interference. This could allow the student to work on his own but still have an accurate trace to duplicate.

It is also possible to use the instrument with a Language Master, although there would be some interference factor involved.

If for some reason permanent records of the traces should be desired, it also possible to use the Visi-Pitch with a chart recorder.

\section{Immediate Feedback}

In all of the applications of the Visi-Pitch in pronunciation training, its primary contribution seems to be its real time, or immediate feedback feature. The student can see his mistakes and know just what feature of his pronunciation to correct. He can evaluate his own work quickly and need not feel threatened by someone else telling him he is wrong. When he is correct he will know it, and can speak with the confidence that comes from knowing that (he is) right. 